\title{
A RELAÇÃO ENTRE GÊNERO E ADESÃo À ATIVIDADE FÍSICA NO LAZER
}

\author{
Marco Antonio Bettine de Almeida, Universidade de São Paulo - USP, São Paulo - Brasil \\ Luzia Mêire Ferreira Rall, Universidade de São Paulo - USP, São Paulo - Brasil \\ Ronailde de Souza Braga, Universidade de São Paulo - USP, São Paulo - Brasil \\ Roseli Joana Celino, Universidade de São Paulo - USP, São Paulo - Brasil
}

\section{RESUMO}

Apresentar-se-á uma explanação acerca da construção social do gênero. A seguir fez-se um breve relato sobre o formato de atividade física dispensada às mulheres e homens de acordo com o gênero. Reflete-se sobre a adesão como um processo influenciado pela estrutura social onde o sujeito está inserido. Resultados de análises estatísticas descritivas sobre adesão à atividade física são apresentados como forma de demonstrar os reflexos das construções sociais. Conclui-se que é necessária a realização de pesquisas que apontem associações entre os dados apresentados quantitativamente e as relações sociais entre homens e mulheres na contemporaneidade, a fim compreender o comportamento em relação à atividade física no lazer e programar estratégias que promovam mudanças efetivas no quadro atual.

Palavras-Chave: Gênero; Adesão; Atividade física; Lazer.

\section{THE RELATIONSHIP BETWEEN GENDER AND ADHERENCE TO PHYSICAL ACTIVITY DURING LEISURE}

\begin{abstract}
Present will be an explanation about the social construction of gender. The following is a brief account of the shape of physical activity given to women and men according to gender. Reflected on the membership as a process influenced by the social structure where the subject is found. Results of descriptive statistical analysis on adherence to physical activity are presented in order to demonstrate the reflections of the social constructions. We conclude that it is necessary to carry out studies that show associations between the data presented quantitatively and social relations between men and women in contemporary society, in order to understand behavior in relation to physical activity during leisure and program strategies to promote effective change within current.
\end{abstract}

Key-Words: Gender; Membership; Physical activity; Leisure. 


\section{INTRODUÇÃO}

Este estudo objetivou investigar a relação entre a adesão à prática de atividade física no tempo de lazer, e a influência que o fator gênero pode exercer sobre ela. Partiu-se da hipótese de que indivíduos do sexo feminino apresentavam maior adesão a essa prática. Entretanto, dados estatísticos demonstraram o oposto, ou seja, que indivíduos do sexo masculino têm maior prevalência de atividade física no tempo de lazer.

Assim, buscou-se na história, e em suas entrelinhas, uma explicação que fundamentasse a diferença comportamental entre homens e mulheres em relação à adesão à prática de atividade física no lazer.

Apresenta-se a seguir uma explanação sobre como a questão do gênero resulta de processos socialmente construídos, bem como o resultado de tal construção direciona as modalidades físicas adequadas para um e outro sexo.

Discute-se acerca da adesão, abordando-a com um fator resultante de determinantes culturais e sociais e, portanto, passível de sofrer influência do gênero, já que este direciona os indivíduos a escolhas que lhes apresentam significado de acordo com a estrutura onde estão inseridos.

Em seguida, são apresentados resultados de análises estatísticas que refletem na atualidade o resultado dos processos sociais e culturais que permanecem preservados na relação homemmulher.

\section{GÊNERO: UMA CONSTRUÇÃO SOCIAL}

De acordo com Vaistman ${ }^{1}$ as diferenças entre sujeitos, que se desenvolvem como parte dos sistemas sociais e simbólicos, dentro dos quais hierarquias entre determinadas categorias sociais são construídas, refletem a discussão sobre gênero.

Para Miranda, ${ }^{2}$ gênero refere-se aos papéis veiculados por uma sociedade, que regem comportamentos predeterminados como apropriados e característicos de homens e de mulheres. Deste modo, a diferença entre sexo e gênero poderá compreender-se melhor quando se pensa na distinção entre identidade sexual e identidade de gênero. A primeira incide sobre os traços genéticos diferenciados de cada sexo. Já a segunda se relaciona com uma identidade 
psicossocial assentada nos valores, comportamentos e atitudes considerados apropriados pela sociedade em função do sexo biológico, mas que também incide muitas vezes sobre o corpo, uma vez que mexe com as gestualidades e toda a simbologia presente nas várias formas de ver e mostrar o corpo.

De acordo com Hoffmann e Harris, ${ }^{3}$ "genero é um conjunto de normas ou expectativas sobre como nos comportamos e estes são associados com as compreensões sociais de sexualidade e procriação" (p.192).

Embora não com exclusividade, não é difícil observar que homens e mulheres não ocupam posições iguais na sociedade brasileira. A identidade dos sexos é construída por meio da distribuição de distintos papéis que aquela espera ver cumpridos pelas diferentes categorias de sexo. A sociedade investe muito na naturalização deste processo, que pode tornar a vida da mulher mais ou menos difícil, como por exemplo, ao imputar-lhe a responsabilidade última pela casa e pelos filhos, mesmo desempenhando função remunerada fora do lar. ${ }^{4}$

De acordo com Castellani Filho ${ }^{5}$ a compreensão de que as atitudes femininas são determinadas pela influência das suas características biológicas, serviu de anteparo à ideia dominante da superioridade do sexo masculino sobre o feminino, afastando qualquer alusão ao fato de tal superioridade estar calcada em determinantes socioculturais e não biofisiológicos.

\section{ATIVIDADE FÍSICA PARA MULHERES}

"Quem conhece educação física e sabe, pois, quais os esportes que a mulher pode e deve praticar, dadas as suas condições fisiológicas, pasma ante tal "espetáculo" que se quer levar a cabo"6 (p. 13).

O "espetáculo" referido se trata de uma partida de futebol feminina realizada no Pacaembu entre paulistas e cariocas. De fato o evento não ocorreu graças à pressão pública gerada por certa carta endereçada ao Presidente da República, Getúlio Vargas. O discurso médico da época condenou a prática do futebol feminino, indicando que além de outras consequências de ordem traumática, este poderia comprometer seriamente os órgãos da reprodução. ${ }^{6}$ 
Todavia, a prática de exercícios físicos pelas mulheres, no final do século XIX, foi instigada, desde que a atividade respeitasse suas formas feminis. É o que nos relata Goellner: ${ }^{7}$

\footnotetext{
Nada mais pertinente do que indicar a exercitação física, dado que sua prática poderia possibilitar o desenvolvimento orgânico e social das mulheres, tornando-as mais fortes, saudáveis e aptas para os desafios de uma sociedade que se modernizava a passos rápidos e empolgantes (p. 273).
}

Os desafios da sociedade a que se refere Goellner, para a mulher, se resumiam na obrigação de gerar uma prole saudável, de tal modo que a figura feminina não aparece desvinculada da de mãe e esposa, ao contrário, as atividades físicas propostas para as mulheres deveriam aperfeiçoar suas condições de parideira. De acordo com Soares, ${ }^{8}$ a mulher passa a ser preparada para a vida familiar e para o casamento.

No decorrer do século XX, ocorreram transformações econômicas, culturais e tecnológicas na sociedade, entretanto, como pode ser observado no início deste tópico, as funções da mulher, bem como os espaços sociais a elas destinados continuaram delimitados.

Não por acaso, Goellner" afirma que "não é raro ainda hoje encontrarmos em escolas de primeiro e segundo graus disparidades relevantes no que se refere ao acesso de meninas e meninos nas atividades físicas realizadas nas aulas de educação física” (p. 291). A autora acrescenta "que esta mesma situação pode ser observada nos espaços de lazer, na gestão esportiva, nos investimentos de clubes e em diversas instâncias onde o esporte se desenvolve"7 (p. 291).

\section{ATIVIDADE FÍSICA PARA HOMENS}

A educação física como elemento educacional enfrentou barreiras arraigadas nos valores dominantes do período colonial, por vinculá-la ao trabalho manual, físico, desprestigiado em relação ao trabalho intelectual. Entretanto, em seu sentido lúdico, de preenchimento do ócio e do tempo livre foi valorizada pela classe dominante. Tal perspectiva acerca da atividade física possibilitou sua entrada nos colégios que assistiam aos filhos da elite, que em se tratando do sexo masculino, recebeu pouca ou nenhuma resistência, já que os pais estavam acostumados à ideia de Ginástica para homens. ${ }^{5}$ 
De acordo com Castellani Filho, ${ }^{5}$ a edição da revista Educação Physica de março de 1934, traz em seu editorial: "[...] a educação física cientificamente fundamentada, mostrando a importância, o valor, o papel do exercício na idade pubertária, para a formação do Homem moderno [...]" (p. 54-56). Está presente também em artigos, a importância da educação física na eugenização da raça brasileira, que no caso dos homens, estariam mais aptos a defenderem e construírem a Pátria.

Uma vez que a história da Educação Física se confunde em muitos momentos com a das instituições militares ${ }^{8}$ não é de se estranhar que os homens tenham recebido maior incentivo à prática de atividade física, bem como se apropriado de determinadas modalidades esportivas e os espaços sociais destinados à sua prática, afinal somente em 1980, por meio da Lei 6.807/80 as mulheres puderam ingressar nas Forças Armadas. ${ }^{9}$

A sociedade moderna esperava do homem a força e coragem para a defesa e construção da pátria. Tanto que diversos decretos específicos para as escolas militares estabeleceram a obrigatoriedade de algumas práticas esportivas naqueles estabelecimentos. ${ }^{10}$

\section{SOBRE ADESÃO}

As pessoas têm que tomar diversas decisões como a que horas levantar, o que vestir, que tarefas realizar (na escola ou no trabalho) e o que fazer nas horas de lazer. Apesar de tais atividades diferirem em relação ao conteúdo e importância, o processo de escolha compartilha uma estrutura comum: dentre um rol de opções, o sujeito escolhe a que faz mais sentido para alcançar o seu objetivo. ${ }^{11}$

De acordo com Ferreira e Najar ${ }^{12}$ o campo de estudo que busca compreender os condicionantes e as consequências da adesão ao exercício físico ainda é pequeno diante de sua importância, principalmente no Brasil, e não pode ser visto como domínio exclusivo de uma área de conhecimento específica, já que a compreensão e eventual alteração do quadro atual requerem ações de larga abrangência, envolvendo profissionais de várias áreas, que tenham em comum o interesse em difundir a atividade física.

Dado o exposto, a história e a sociologia são áreas do conhecimento das ciências humanas que podem ajudar a compreender a influência do gênero, cuja construção foi anteriormente 
suscitada, no que se refere à adesão à prática de atividade física, já que socialmente - sob um pano de fundo biológico - as atividades físicas foram sendo atribuídas a homens e mulheres de acordo com o sexo.

Para Aota citado por Pfeifer; Martins e $\operatorname{Santos}^{11}$ ocupação pode ser compreendida como atividades diárias que refletem valores culturais e fornecem estrutura e significado à vida da pessoa. Estas fazem parte das necessidades humanas de autocuidado, satisfação e participação na sociedade.

Se dentro da estrutura social são delegados à mulher os papéis de mãe e esposa, e, portanto o espaço doméstico, suas escolhas para o lazer poderão estar vinculadas aos espaços destinados ao sexo feminino, que lhe conferirão significado. O mesmo deve ocorrer com indivíduos do sexo masculino, cujas funções sociais, a de trabalhador e chefe de família lhe permitem o conhecimento e apropriação de espaços sociais diferentes do doméstico.

\section{REFLEXOS DA HISTÓRIA}

Uma pesquisa epidemiológica realizada com indivíduos adultos na área rural de Minas Gerais revelou que os homens foram mais ativos que as mulheres no lazer, deslocamentos e trabalho, enquanto as mulheres foram mais ativas no ambiente doméstico. Relatando especificamente o resultado obtido sobre a atividade física no domínio do lazer, o percentual de indivíduos que atingiu os 150 minutos semanal, conforme indíce da Organização Mundial de Saúde, foi cerca de três vezes maior entre os homens em comparação às mulheres. ${ }^{13}$

As relações encontradas entre atividade física e sexo, em geral, repetem o padrão mostrado em estudos realizados em áreas urbanas, nos quais homens são mais ativos que mulheres no domínio do lazer. ${ }^{13}$

Em estudo realizado com funcionários de uma universidade pública no Rio de Janeiro, no qual 3.740 indivíduos de ambos os sexos responderam questionário acerca da atividade física no lazer (AFL), encontrou resultados semelhantes ao da pesquisa supracitada, os quais demonstram um domínio masculino na prática de AFL. Os autores destacam que os homens se engajaram mais em atividades físicas coletivas e de caráter competitivo do que as mulheres, que preferiram atividades individuais, que requerem do corpo menos força física e apontam 
que uma possível explicação para tal comportamento, pode ser relacionada à dupla jornada de trabalho das mulheres, que além da ocupação profissional, assumem as responsabilidades domésticas. ${ }^{1}$

De acordo com Esculcas ${ }^{14}$ a acessibilidade às práticas de atividade física no tempo de lazer é claramente dependente de um conjunto de factores, entre os quais o sexo e a idade. Assim, não poderíamos deixar de apontar a influencia de gênero na adesão a atividade física em uma faixa etária diferente da adulta até agora apresentada.

Um estudo de revisão realizado por Seabra, ${ }^{15}$ o qual analisou fatores determinantes para a prática de atividade entre adolescentes, apontou o gênero como fator determinante para o nível de atividade física destes, sendo evidente que o sexo masculino está mais envolvido em atividades físicas que os seus pares do sexo oposto.

\section{CONSIDERAÇÕES FINAIS}

Embora muitas pesquisas se debrucem sobre a questão da adesão à atividade física no lazer e considerem as diferenças entre a prevalência de homens e mulheres em seus resultados estatísticos, pouquíssimos estudos se preocupam em buscar explicações para este comportamento.

Apesar de reconhecer a importância de estudos descritivos estatísticos, uma vez que estes indicam de forma prática a situação real de determinada população, se faz urgente a realização de pesquisas que busquem estabelecer associações entre os números apresentados e a cultura local, por exemplo.

Sabe-se hoje que muitas mulheres deixaram de restringir suas funções ao âmbito doméstico e assumiram atividades ocupacionais no mercado de trabalho. Ou seja, o modelo familiar sofreu profundas transformações de ordem estrutural e muitas vezes indivíduos do sexo feminino assumem a função de chefe de família.

Dado o exposto, o comportamento apresentado - por meio dos estudos estatísticos - pelas mulheres em relação à atividade física no tempo de lazer, demonstra resquícios da estrutura 
familiar de caráter patriarcal. Mesmo entre adolescentes, onde teoricamente a ocupação laboral não se faz presente, há a reprodução dos resultados encontrados em adultos.

A compreensão das relações sociais entre homens e mulheres na contemporaneidade faz-se necessária para auxiliar nas políticas públicas de incentivo à prática de atividade física, posto ser o processo de adesão fortemente influenciado pelo fator gênero, e, portanto, determinante para se programar estratégias que promovam mudanças efetivas no quadro atual.

\section{REFERÊNCIAS}

${ }^{1}$ SALLES-COSTA, R. et al. Gênero e prática de atividade física de lazer. Caderno de Saúde Pública, Rio de Janeiro, 2011. Disponível em: <http://www.scielo.br/scielo.php >. Acesso em: 21 maio 2011.

${ }^{2}$ MIRANDA, P. A construção social das identidades de género nas crianças: um estudo intensivo em Viseu. In: CONGRESSO PORTUGUÊS DE SOCIOLOGIA, 6., Lisboa, 2008. Anais... Lisboa, 2008. Disponível em: <http://www.aps.pt/vicongresso/pdfs/136.pdf >. Acesso em: 30 maio 2011.

${ }^{3}$ HOFFMAN, S. J.; HARRIS, J. C. Cinesiologia: o estudo da atividade física. Porto Alegre: Artmed, 2002. 487p.

${ }^{4}$ SAFFIOTI, H. I. B. O poder do macho. São Paulo: Moderna, 1987. 134p.

${ }^{5}$ CASTELlANI FILHO, L. C. Educação física no Brasil: a história que não se conta. 10. ed edição. Campinas: Papirus, 2004. 224p.

${ }^{6}$ FRANZINI, F. Futebol é "coisa para macho"?: Pequeno esboço para uma história das mulheres no país do futebol. Revista Brasileira de História, São Paulo, v. 25, n. 50, dez. 2005. Disponível em: <http://www.scielo.br/scielo.php>. Acesso em: 08 jun. 2011. 
${ }^{7}$ GOELLNER, S. V. Imagens da mulher no esporte. In: PRIORE, M. D.; MELO, V. A. (Org.). História do esporte no Brasil: do império aos dias atuais. São Paulo: Ed. da Unesp, 2009. $568 \mathrm{p}$.

${ }^{8}$ SOARES, C. L. Educação Física: raízes européias e Brasil. 2. ed. Campinas: Autores Associados, 2001. 143p.

${ }^{9}$ BRASIL. Câmara dos Deputados. Homenagem, Câmara lembra 30 anos do ingresso da mulher na Marinha. Disponível em: <http://www.camara.gov.br/internet/jornalcamara >. Acesso em: 11 jun. 2011.

${ }^{10}$ TUBINO, M. J. G. 500 anos de legislação esportiva brasileira: do Brasil colônia ao início do século XXI. Rio de Janeiro: Shape, 2002. 282p.

${ }^{11}$ PFEIFER, L. I.; MARTINS, Y. D.; SANTOS, J. L. F. A influência socioeconômica e de gênero no lazer de adolescentes. Psicologia: teoria. e pesquisa, Brasília, v. 26, n. 3, set. 2010. Disponível em: <http://www.scielo.br/scielo.php> Acesso em: 21 maio 2011.

${ }^{12}$ FERREIRA, M. S.; NAJAR, A. L. Programas e campanhas de promoção da atividade física. Ciência \& Saúde Coletiva, Rio de Janeiro, 2011. Disponível em: <http://www.scielo.br/scielo.php>. Acesso em: 06 abr. 2011.

${ }^{13}$ BICALHO, P. G. et al . Atividade física e fatores associados em adultos de área rural em Minas Gerais, Brasil. Revista de Saúde Pública, São Paulo, v. 44, n. 5, out. 2010. Disponível em: <http://www.scielo.br/scielo.php>. Acesso em: 08 jun. 2011.

${ }^{14}$ ESCULCAS, C.; MOTA, J. Actividade física e práticas de lazer em adolescentes. Revista Portuguesa de Ciencias do Desporto, v. 5, n.1, p. 69-76, jan. 2005. Disponível em: <http://www.scielo.oces.mctes.pt >. Acesso em: 21 maio 2011.

${ }^{15}$ SEABRA, A. F. et al. Determinantes biológicos e sócio-culturais associados à prática de atividade física de adolescentes. Caderno de Saúde Pública, Rio de Janeiro, v. 24, n. 4, abr. 2008. Disponível em: <http://www.scielo.br/scielo.php >. Acesso em: 23 abr. 2011. 